\title{
Iron supply of staphylococci and of micrococci by $\alpha$-ketoacids
}

\author{
DAGMAR HEUCK, W. BEER and R. REISSBRODT*
}

Robert Koch Institute, Wernigerode Branch, D-38855 Wernigerode, Germany

\begin{abstract}
Summary. Most of 232 strains of coagulase-negative staphylococci (CNS) belonging to 16 species, and nine strains of micrococci belonging to four species, could be distinguished by their growth on an iron-poor nutrient medium. $\alpha$-Keto- $/ \alpha$-hydroxyacids, as primary metabolites, facilitated iron supply to CNS and micrococci under various iron-limited conditions, as detected by different bioassay methods. Twelve selected CNS strains and two micrococcal strains produced significant amounts of $\alpha$-ketoacids in iron-poor liquid nutrient media. In particular, strains of Staphylococcus cohnii, S. xylosus and S. lentus unable to grow on iron-poor media, produced high amounts of pyruvic acid and $\alpha$-ketoglutaric acid. In bioassays, the selected CNS strains being siderophore indicator strains were fed with $\alpha$ ketoacids at different levels of iron limitation. Strains able to grow under iron deprivation appeared to produce additional siderophores such as staphyloferrins under iron stress. $\alpha$ Keto-/ $\alpha$-hydroxyacids may be additionally active in the iron supply of CNS and micrococci.
\end{abstract}

\section{Introduction}

Coagulase-negative staphylococci (CNS) are normal flora of the surface of the human and animal body, and are most commonly encountered as commensal bacteria. The number of reports dealing with nosocomial CNS infection has increased enormously in recent years. If local or general host defence mechanisms are impaired or if foreign bodies such as prosthetic devices, indwelling catheters or shunts are present in the host, CNS may cause severe infection such as septicaemia and endocarditis. ${ }^{1}$ Furthermore, in many patients undergoing treatment for renal failure by continuous ambulatory peritoneal dialysis, CNS are the predominant cause of acute, persistent or recurrent peritonitis."

The emergence of CNS as significant pathogens has aroused much interest in the characterisation of possible virulence determinants. Iron concentration influences the expression of several genes involved in iron uptake and virulence in bacteria. ${ }^{3.4}$ For several micro-organisms, a correlation between siderophore production and virulence has been demonstrated. ${ }^{5}$ For this reason. there is an increasing interest in strategies of iron acquisition in CNS.

Recently, Meiwes et al. ${ }^{6}$ and Konetschny-Rapp et $a l .^{3}$ described the isolation and structure elucidation of

Received 27 Sept. 1994: revised version accepted 15 Jan. 1995. *Correspondence should be sent to Dr R. Reissbrodt. a novel siderophore from S. hyicus DSM 20459, named staphyloferrin A. It belongs to the polycarboxylatetype siderophores, as described by Smith et al. ${ }^{7}$ Drechsel et al. ${ }^{8}$ and Haag et al. ${ }^{9}$ described the purification, characterisation and biological properties of a second siderophore found in staphylococci named staphyloferrin B. It was also isolated from $S$. hyicus DSM 20459 and is produced by a large variety of staphylococci.

Additionally, staphylococci are able to utilise other iron sources including ferric citrate, host iron compounds such as transferrin, lactoferrin and haemoglobin $^{10}$ and exogenous siderophores, mostly of the hydroxamate-type, e.g., ferrioxamines, ferrichromes. ${ }^{11}$ In an agar diffusion test, the staphylococci were shown to utilise dihydroxamate-type siderophores ${ }^{10}$ and with the exception of all strains of S. epidermidis and some strains of $S$. hominis and $S$. capitis, ${ }^{12}$ trihydroxamatetype siderophores. Marcelis et al. ${ }^{13}$ concluded from agar-diffusion tests with staphylococcal cell suspensions that siderophores, which could not be utilised by gram-negative bacteria, were excreted.

Little information is available about iron uptake by staphylococci. Like gram-negative bacteria, staphylococci synthesise some additional cell-wall proteins and cytoplasmic proteins (known as iron-repressible cytoplasmic membrane proteins, IRMPs) under irondeficient conditions. ${ }^{2.14 .15}$ Their significance as potential iron transport proteins has not been elucidated. Studies of growth promotion and iron transport 
have revealed that certain $\alpha$-ketoacids and $\alpha$-hydroxyacids, generated by amino-acid deaminases as primary metabolites, show significant siderophore activity. ${ }^{16-19}$ Enterobacteriaceae of the Proteus-ProvidenciaMorganella group, Salmonella spp., Yersinia enterocolitica, even Escherichia coli, as well as Pasteurella spp. ${ }^{20}$ use their iron-binding properties under ironlimited conditions for iron supply.

This paper reports studies with $\alpha$-ketoacids and $\alpha$ hydroxyacids acting as siderophores of CNS and of two species of micrococci. They are produced as primary metabolites by CNS and can be utilised, from exogenous sources, by different species of CNS.

\section{Materials and methods}

\section{Bacterial strains}

The 282 strains studied belonged to the species $S$. aureus (41 isolates), 16 different species of CNS (232) and to four different species of micrococci (9) (table II). They were taken from the collection of the Robert Koch Institute, Wernigerode Branch, Germany. All strains were identified by classical methods according to $\mathrm{Kloos}$ and $\mathrm{Lambe}^{21}$ and by the micro-method developed by Braulke et $a .^{22}$ and freshly cultivated on nutrient agar at $37^{\circ} \mathrm{C}$ overnight before use.

S. epidermidis ATCC 14990 was used as the indicator strain in the bioassays described below.

\section{$\alpha$-Ketoacids (1-oxoacids), $\alpha$-hydroxyacids and other siderophores}

Ferrioxamines B, E (FoB, E) were kindly provided by Dr H. H. Peter, Ciba Geigy, Basel, Switzerland; ferrioxamine $\mathrm{G}$ (FoG) was isolated and purified from Hafnia alvei according to Reissbrodt et al. (1990), ${ }^{23}$ enterobactin (ENT) was produced from $E$. coli according to the method of Neilands and Nakamura $;{ }^{24}$ rhizoferrin, ferrichrome and staphyloferrin A were kindly provided by G. Winkelmann, University of Tübingen, Tübingen, Germany; pyruvic acid (PA) was purchased from E. Merck GmbH, Darmstadt, Germany; $\delta$-aminolevulinic acid, DL- $\alpha$-keto- $\beta$-methylvaleric acid (KMV), oxalacetic acid (OXO), $\alpha$-ketoisocaproic acid (KIC), $\alpha$-ketoadipic acid (KAA), $\alpha$ hydroxyisovaleric acid (OH-IV), $\beta$-phenylpyruvic acid (PPA), $\beta$-indolpyruvic acid ( $\beta$-IP), $\alpha$-ketoglutaric acid (KGA), $\alpha$-ketobutyric acid (KBA), $\alpha$-ketoisovaleric acid (KIV) and $\alpha$-ketomalonic acid (KMA) were purchased from Sigma. The purity of siderophores was confirmed by high-performance liquid chromatography (HPLC) as described previously. ${ }^{25,26}$

\section{Nutrient media}

Bioassay medium (medium 1). A modification of the bioassay medium described by Meiwes et al. ${ }^{6}$ was used. This medium comprised two components : firstly
Casamino acids (Difco) $2.5 \mathrm{~g}$, Bacto agar (Difco) $7.5 \mathrm{~g}$ in $250 \mathrm{ml}$ double-distilled water, and secondly glucose $5.0 \mathrm{~g}, \mathrm{MgSO}_{4} .7 \mathrm{H}_{2} \mathrm{O} 50 \mathrm{mg}, \mathrm{CaCl}_{2} .6 \mathrm{H}_{2} \mathrm{O} 2.9 \mathrm{mg}$, Ntris(hydroxymethyl)-methyl-2-aminoethanesulphonic acid $7.5 \mathrm{~g}, \mathrm{KH}_{2} \mathrm{PO}_{4} 500 \mathrm{mg},\left(\mathrm{NH}_{4}\right)_{2} \mathrm{SO}_{4} 1 \mathrm{~g}$ and $\mathrm{NaCl}$ $2.5 \mathrm{mg}$ in $250 \mathrm{ml}$ of double-distilled water. Both components were combined after sterilisation and the $\mathrm{pH}$ was adjusted to $7 \cdot 5$. A sterile stock solution $(0.5 \mathrm{ml})$ of vitamins (mg/1 final concentration: folic acid 10; biotin 6; p-aminobenzoic acid 200; thiamin $\mathrm{HCl} \mathrm{1000;}$ pantothenic acid 1200 ; riboflavin 1000 ; nicotinic acid 2300; pyridoxin $\mathrm{HCl} 12000$; vitamin B12 100) was added. Finally, deferrated ethylenediaminedi-(ohydroxyphenylacetic acid) (EDDHA; Sigma) $15 \mathrm{mg}$, purified according to $\operatorname{Rogers}^{27}$, was added for iron stress. Molten agar at $45^{\circ} \mathrm{C}$ was inoculated with an 18-h culture of the siderophore indicator strain S. epidermidis ATCC 14990 in nutrient broth (1 ml/ $100 \mathrm{ml}$ ).

Chemically defined medium (CDM-H; medium 2). This modified, chemically defined medium according to Flossmann et al. ${ }^{28}$ contained $(/ 1 \mathrm{~L}$ final concentration): $\mathrm{NaH}_{2} \mathrm{PO}_{4} .12 \mathrm{H}_{2} \mathrm{O}, 32.3 \mathrm{~g} ; \mathrm{KH}_{2} \mathrm{PO}_{4}, 1.36 \mathrm{~g}$; $\mathrm{NaCl}, 1.19 \mathrm{~g}$; glucose $6.0 \mathrm{~g}$; L-arginine, $0.2 \mathrm{~g}$; Lcysteine hydrochloride $0.12 \mathrm{~g}$; L-serine, $0.2 \mathrm{~g}$; Lglutamic acid, 0.15 g; L-isoleucine, $0.065 \mathrm{~g}$; L-leucine, $0.065 \mathrm{~g}$; L-phenylalanine, $0.095 \mathrm{~g}$; calcium pantothenate, $0.002 \mathrm{~g}$; nicotinic acid amide, $0.005 \mathrm{~g}$; thiamine hydrochloride, $0.0001 \mathrm{~g}$; orotic acid, $0.0015 \mathrm{~g}$ dissolved in $400 \mathrm{ml}$ of double-distilled water, and a second component of $\mathrm{MgSO}_{4} .7 \mathrm{H}_{2} \mathrm{O}, 0.25 \mathrm{~g}$; Laspartic acid, $1.6 \mathrm{~g}$; L-tyrosine, $0.09 \mathrm{~g}$ dissolved in $600 \mathrm{ml}$ of double-distilled water. These solutions were combined after sterilisation and the $\mathrm{pH}$ was adjusted to $7 \cdot 3$.

A sterile stock solution $(0 \cdot 1 \mathrm{ml})$ of vitamins $(\mathrm{mg} /$ $10 \mathrm{ml}$ final concentration: Ca-pantothenate, 20 ; nicotinamide, 50; thiamin. $\mathrm{HCl}, 1$; orotic acid, 15) was added. Finally, yeast extract $0.5 \mathrm{~g}$ and purified agar (Oxoid, Agar No. 1) $1 \mathrm{~g}$ dissolved in $20 \mathrm{ml}$ of doubledistilled water and sterilised were added. This agar medium was seeded $(100 \mu \mathrm{l} / 10 \mathrm{ml})$ with an $18-\mathrm{h}$ culture of selected strains in nutrient broth.

Conalbumin $/ \alpha, \alpha^{\prime}$-bipyridyl-medium. Conalbumin plates were prepared according to Stevenson and Griffith. ${ }^{29}$ The agar $(13 \mathrm{ml} /$ plate $)$ contained $6.5 \mathrm{ml}$ of double concentrated Trypticase Soy Agar (BBL), $0.65 \mathrm{ml}$ of conalbumin (ovotransferrin solution, Sigma $44 \mathrm{mg} / \mathrm{ml})$ and $0.45 \mathrm{ml}$ of $\mathrm{NaHCO}_{3}(0.71 \mathrm{M})$ dissolved in $5.4 \mathrm{ml}$ of double-distilled water (final concentration of conalbumin, $1.0 \mathrm{~g} / \mathrm{L}) ; 100 \mu \mathrm{M} \alpha, \alpha^{\prime}-$ bipyridyl was added for iron limitation. The same components were added to Tryptic Soy Broth (BBL)for liquid medium.

\section{Growth of different CNS and micrococcal strains in iron poor media}

Growth on conalbumin $/ \alpha, \alpha^{\prime}$-bipyridyl-plates. Growth for the identification of surviving mechanisms under 
iron-limited conditions was tested on conalbumin/ $\alpha, \alpha^{\prime}$-bipyridyl-plates as described above. Forty-one $S$. aureus strains, $232 \mathrm{CNS}$ and nine micrococcal strains (table II) freshly grown for $48 \mathrm{~h}$ at $37^{\circ} \mathrm{C}$ on Mueller-Hinton Agar (Oxoid) with sheep blood 5\% and with a bacterial density of $c .3 \times 10^{8} \mathrm{cfu} / \mathrm{ml}$ were starved in $0.5 \mathrm{ml}$ of Tris-buffer, $\mathrm{pH} 7 \cdot 4$. After $30 \mathrm{~min}$ at $37^{\circ} \mathrm{C}$, the starved strains were spot inoculated on to conalbumin $/ \alpha, \alpha^{\prime}$-bipyridyl-plates. Growth was read after incubation for $24 \mathrm{~h}$ at $37^{\circ} \mathrm{C}$ (tables II and IV).

Growth in liquid conalbumin/x. $x^{\prime}$-bipyridyl-medium. For testing the individual ability to produce endogenous chelators. selected strains (table IV) were cultivated in $2 \mathrm{ml}$ of conalbumin/ $\alpha, \alpha^{\prime}$-bipyridyl liquid medium with shaking overnight at $37^{\circ} \mathrm{C}$. After centrifugation ( $10 \mathrm{~min}$ at $3000 \mathrm{rpm}$ ) supernates were taken to prepare paper disks ( $20 \mu \mathrm{l} /$ disk of $6 \mathrm{~mm}$ diameter) for bioassays and also used for determination of $x$ ketoacids by HPLC.

\section{Bioassays}

Bioassays (also designated as cross-feeding tests) were performed by modifications of the methods described by Miles and Khimji ${ }^{30}$ and Reissbrodt and Rabsch $^{31}$ with the two different bioassay media (1 and 2).

Bioassay of supernates of CNS and micrococci on S. epidermidis ATCC 14990. Bioassay medium 1 was seeded with S. epidermidis ATCC $14990(1 \mathrm{ml} / 100 \mathrm{ml})$ to demonstrate siderophore activity of the selected CNS and micrococcal strains. Filter paper disks were loaded with supernates of these strains and placed on the solidified agar which were incubated at $37^{\circ} \mathrm{C}$ for $18 \mathrm{~h}$. A halo of growth surrounded those disks carrying siderophore activity.

Bioassay of siderophores/ $\alpha$-ketoacids/ $\alpha$-hydroxyacids on S. epidermidis ATCC 14990. Medium 2 was used to prove the iron chelating effect of diverse siderophores and $x$-keto- $/ \alpha$-hydroxyacids in bioassays. Filter paper disks were loaded with siderophore solutions $(1 \mathrm{mg} / \mathrm{ml}), 5 \mu \mathrm{l}$ each in the case of natural siderophores and $10 \mu \mathrm{l}$ each of $\alpha$-keto-/ $\alpha$-hydroxyacids. Growth around the disks demonstrated siderophore activity.

Bioassay of $\alpha$-ketoacids, ferrioxamine $B$ and enterobactin on several $C N S$ strains under different conditions of iron limitation by EDDHA. Bioassays of selected $\alpha-$ ketoacids and siderophores listed in table III on the CNS strains were performed with medium 2 . The individual ability of the CNS strains which had been shown to utilise these siderophores by use of corresponding uptake systems was to be tested. Therefore, the amount of EDDHA in medium 2 was increased from $10 \mu \mathrm{M}$ to a final $100 \mu \mathrm{M} /$ plate.

\section{Determination of $\alpha$-ketoacids by HPLC}

Six strain-pairs of four CNS species and two micrococcal species (growing and non-growing strains) were selected (table IV). These 14 strains were analysed by HPLC for their $\alpha$-ketoacid composition according to Hayashi et al. ${ }^{26}$ The $\alpha$-ketoacids were determined as $Q$ values. $Q$ value was defined as

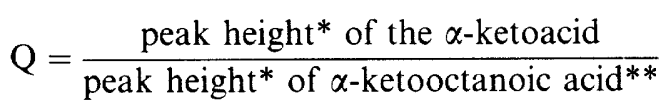

where ${ }^{*}$ showed as 2 -chinoxalinoles and ${ }^{* *}$ was the internal standard $(120 \mathrm{nmol})$.

\section{Results}

Bioassays and growth of staphylococci and micrococci under different iron-deprived conditions

The polycarboxylate-type siderophores rhizoferrin and staphyloferrin $\mathrm{A}, \delta$-aminolevulinic acid and two $x$-keto- $/ x$-hydroxyacids cross-fed $S$. epidermidis ATCC 14990 in bioassays (table I). The trihydroxamate-type siderophores ferrioxamine B, E, G and ferrichrome, as well as the catecholate-type siderophore enterobactin did not cross-feed; $\beta$-indolepyruvic acid inhibited this strain.

Thirty-four of 241 different strains of CNS and micrococci tested did not grow on iron-depleted conalbumin $/ \alpha, \alpha^{\prime}$-bipyridyl medium (table II). Of the many strains tested, the common species $S$. epidermidis and S. haemolyticus grew on this iron-limited medium, although all the $S$. epidermidis strains grew poorly. All $41 S$. aureus strains were able to overcome this iron limitation and grew well. Among the other species tested, strains showed varied ability to grow on irondepleted media. This individual ability is described either as growing $(+)$ or non-growing $(-)$.

Twelve CNS strains and two micrococcal strains were selected and used as pairs of growing or nongrowing organisms in further investigations (table IV). These 14 strains were able to grow in shaken liquid conalbumin $/ \alpha, \alpha^{\prime}$-bipyridyl medium, and supernates of these cultures cross-fed S. epidermidis ATCC 14990 used in the bioassays.

Bioassays were also performed by seeding the CNSstrains listed in table IV as siderophore indicator

Table I. Bioassay with different siderophores on $S$. epidermidis ATCC 14990

\begin{tabular}{l} 
Siderophore tested \\
\hline Ferrioxamines B, E, G \\
Enterobactin \\
Rhizoferrin \\
Staphyloferrin A \\
Ferrichrome \\
$\delta$-Aminolevulinic acid \\
$\alpha$-Ketoisocaproic acid \\
$\alpha$-Ketoisovaleric acid \\
$\beta$-Phenylpyruvic acid \\
$\alpha$-Ketoglutaric acid \\
Pyruvic acid \\
DL- $\alpha$-Keto- $\beta$-methylvaleric acid \\
$\alpha$-Hydroxyisovaleric acid \\
$\beta$-Indolepyruvic acid \\
Oxalacetic acid
\end{tabular}

Growth

Oxalacetic acid 
Table II. Growth of $S$. aureus, CNS strains of 16 different species and of micrococci on conalbumin $/ \alpha, \alpha^{\prime}$-bipyridylplates

\begin{tabular}{lccc}
\hline & \multirow{2}{*}{$\begin{array}{c}\text { Number } \\
\text { of }\end{array}$} & \multicolumn{2}{c}{ Number of strains } \\
\cline { 3 - 4 } & strains tested & growing & not growing \\
\hline S. aureus & 41 & 41 & 0 \\
S. epidermidis & 57 & 57 & 0 \\
S. hominis & 25 & 16 & 9 \\
S. capitis & 23 & 11 & 12 \\
S. cohnii & 15 & 13 & 2 \\
S. sciuri & 6 & 6 & 0 \\
S. lentus & 4 & 3 & 1 \\
S. haemolyticus & 14 & 14 & 0 \\
S. intermedius & 10 & 10 & 0 \\
S. warneri & 10 & 9 & 1 \\
S. saprophyticus & 13 & 11 & 2 \\
S. schleiferi & 4 & 4 & 0 \\
S. xylosus & 8 & 7 & 1 \\
S. lugdunensis & 11 & 8 & 3 \\
S. simulans & 22 & 20 & 2 \\
S. chromogenes & 7 & 7 & 0 \\
S. hyicus & 3 & 3 & 0 \\
M. luteus & 4 & 4 & 0 \\
M. roseus & 1 & 1 & 0 \\
M. kristinae & 1 & 0 & 1 \\
M. varians & 3 & 3 & 0 \\
Total & 282 & 248 & 34 \\
\hline
\end{tabular}

strains. Here the cross-feeding test was performed under different conditions of iron limitation by the addition of increasing amounts of EDDHA to medium 2. Table III shows a representative example of these experiments. The $\alpha$-ketoacids KIC, KIV, KMV and $\mathrm{PA}$, as well as ferrioxamine B and enterobactin, crossfed the $S$. lentus strains on iron-limited medium 2. $S$. lentus $609 / 91$ showed growth enhancement by the $\alpha$ ketoacids only up to $40 \mu \mathrm{m}$ EDDHA, above that level the plate was overgrown, probably as a result of the production of staphyloferrins. S. lentus $317 / 91$, while not able to grow on conalbumin $/ \alpha, \alpha^{\prime}$-bipyridyl-plates, showed positive cross-feeding tests under all conditions of iron limitation tested. The same behaviour was detected in the strain-pairs of $S$. xylosus and $S$. cohnii. The $S$. saprophyticus strain-pairs (growing and non-growing) were cross-fed by these $\alpha$-ketoacids under all the iron-deprived conditions tested (10$100 \mu \mathrm{M}$ EDDHA, data not shown). Ferrioxamine B and enterobactin cross-fed all the strains tested under the different iron-limited conditions.

\section{Production of $\alpha$-ketoacids}

Table IV shows the detection of $\alpha$-ketoacids in the supernates of 14 selected strains after cultivation in liquid conalbumin $/ \alpha, \alpha^{\prime}$-bipyridyl nutrient medium. The $\alpha$-ketoacid composition of investigated strains was found to be different within the species-pairs of $S$. xylosus, S. cohnii and S. lentus. Non-growing CNS strains exhibited significantly higher amounts of PA when compared with the growing ones. Similar results were seen for KGA and to a lesser extent for KBA. Production of the other $\alpha$-ketoacids was similar and was independent of growth under conditions of iron limitation. All strains tested produced the $\alpha$-ketoacids PA, KIC and PPA in varying amounts. Besides significant differences in the composition of $\alpha$-ketoacids, the total amounts of $\alpha$-ketoacids produced were significantly higher in these non-growing CNS strains when compared with the growing strains. The $S$. saprophyticus strains, whether capable of growing or not, on conalbumin $/ \alpha, \alpha^{\prime}$-bipyridyl-plates, did not show such differences, although higher amounts of KAA were observed in non-growing strains. Also remarkable was the KMA content of $S$. saprophyticus 358/91 (non-growing) and that of KGA in the growing S. saprophyticus strain 392/91.

The composition of $\alpha$-ketoacids produced by both micrococcal species was similar, independent of their

Table III. Bioassay of two selected $S$. lentus strains, growing $(+)$ or non-growing $(-)$, on conalbumin $/ \alpha, \alpha^{\prime}$-bipyridyl-plates with different iron limitation

\begin{tabular}{|c|c|c|c|c|c|c|c|}
\hline \multirow{2}{*}{ Siderophores } & \multicolumn{7}{|c|}{ Growth zones (mm) of $S$. lentus $609 / 91(+)$ with } \\
\hline & $\begin{array}{c}10 \mu \mathrm{M} \\
\text { EDDHA }\end{array}$ & $\begin{array}{c}15 \mu \mathrm{M} \\
\mathrm{EDDHA}\end{array}$ & $\begin{array}{c}20 \mu \mathrm{M} \\
\text { EDDHA }\end{array}$ & $\begin{array}{c}30 \mu \mathrm{M} \\
\text { EDDHA }\end{array}$ & $\begin{array}{c}40 \mu \mathrm{M} \\
\mathrm{EDDHA}\end{array}$ & $\begin{array}{c}60 \mu \mathrm{M} \\
\mathrm{EDDHA}\end{array}$ & $\begin{array}{c}100 \mu \mathrm{M} \\
\text { EDDHA }\end{array}$ \\
\hline KIC & 22 & 16 & 14 & (6) & 10 & $\mathrm{~g}$ & $\mathrm{~g}$ \\
\hline KIV & 20 & 14 & 14 & (6) & 12 & $\mathrm{~g}$ & $\mathrm{~g}$ \\
\hline KMV & 12 & (8) & 10 & (6) & 10 & $\mathrm{~g}$ & $\mathrm{~g}$ \\
\hline PA & 14 & (6) & (8) & (6) & 10 & $\mathrm{~g}$ & $\mathrm{~g}$ \\
\hline FoB & 32 & 30 & 28 & 30 & 30 & 30 & 30 \\
\hline \multirow[t]{2}{*}{ ENT } & 24 & 24 & 24 & 24 & 24 & 24 & 24 \\
\hline & \multicolumn{7}{|c|}{ Growth zones (mm) of S. lentus $317 / 91(-)$} \\
\hline $\mathrm{KIC}$ & 14 & 16 & $(10)$ & 14 & 14 & 20 & 12 \\
\hline KIV & 12 & $(10)$ & (14) & 18 & 14 & 10 & 12 \\
\hline KMV & 18 & (8) & 20 & 20 & $(12)$ & 14 & 18 \\
\hline PA & 12 & (6) & $(10)$ & 14 & 18 & 18 & 10 \\
\hline FoB & 30 & 30 & 30 & 30 & 30 & 30 & 30 \\
\hline ENT & 24 & 24 & 26 & 28 & 24 & 32 & 28 \\
\hline
\end{tabular}

Figures in parentheses indicate poor growth around the siderophore disks; $g$, equal growth on the entire plate, probably the stronger staphylococcal siderophores (staphyloferrin) enable the strain to grow. For abbreviations see Materials and methods. 
Table IV. Growth of 12 CNS strains and two strains of micrococci on conalbumin $/ \alpha, \alpha^{\prime}$-bipyridyl plates and detection of $\alpha$-ketoacids in supernates of these strains

\begin{tabular}{|c|c|c|c|c|c|c|c|c|c|c|c|}
\hline \multirow{2}{*}{ Strain } & \multirow{2}{*}{$\begin{array}{l}\text { Growth on } \\
\text { conalbumin/ } \\
\alpha, \alpha^{\prime} \text {-bipyridyl }\end{array}$} & \multicolumn{10}{|c|}{$Q$ values of $x$-ketoacids } \\
\hline & & $\mathrm{KGA}$ & KMA & KAA & $\mathrm{PA}$ & KBA & KIV & KIC & KMV & PPA & Total \\
\hline $\begin{array}{c}\text { S. xylosus } \\
679 / 90\end{array}$ & - & 1.89 & 0 & 0 & $32 \cdot 55$ & 0 & 0.09 & $2 \cdot 09$ & 0.24 & $0 \cdot 15$ & 37.01 \\
\hline $\begin{array}{l}\text { S. vilosus } \\
527 / 90\end{array}$ & + & 0.21 & 0 & 0 & 1.86 & 0 & 0.87 & $5 \cdot 68$ & $1 \cdot 51$ & $0 \cdot 22$ & $10 \cdot 35$ \\
\hline $\begin{array}{c}\text { S. cohnii } \\
349 / 91\end{array}$ & + & 0 & $3 \cdot 38$ & 0 & $6 \cdot 60$ & 0 & 0.26 & 1.87 & 0 & $0 \cdot 44$ & $12 \cdot 55$ \\
\hline $\begin{array}{c}\text { S. cohnii } \\
611 / 90\end{array}$ & + & 0 & 0 & $1 \cdot 04$ & $3 \cdot 24$ & 0 & $0 \cdot 12$ & 1.98 & 0 & $0 \cdot 38$ & 6.76 \\
\hline $\begin{array}{c}\text { S. cohnii } \\
469 / 90\end{array}$ & - & 3.53 & 0 & 0 & 87.54 & $1 \cdot 11$ & 0 & $2 \cdot 18$ & 0 & $0 \cdot 40$ & $94 \cdot 76$ \\
\hline $\begin{array}{c}\text { S. cohnii } \\
17 / 91\end{array}$ & - & $17 \cdot 89$ & 0 & 0 & $80 \cdot 58$ & $0 \cdot 64$ & $0 \cdot 33$ & 3.84 & $0 \cdot 32$ & $1 \cdot 21$ & $104 \cdot 81$ \\
\hline $\begin{array}{c}\text { S. lentus } \\
609 / 91\end{array}$ & + & 0 & 0 & 0 & $3 \cdot 13$ & 0 & 0.74 & $4 \cdot 04$ & 0 & 1.91 & $9 \cdot 82$ \\
\hline $\begin{array}{c}\text { S. lentus } \\
317 / 91\end{array}$ & - & $104 \cdot 18$ & 6.59 & $8 \cdot 10$ & $49 \cdot 40$ & 0.37 & $1 \cdot 13$ & 3.09 & 1.22 & $1 \cdot 11$ & $175 \cdot 24$ \\
\hline $\begin{array}{l}\text { S. saprophyticus } \\
392 / 91\end{array}$ & + & $6 \cdot 14$ & 0.68 & 0 & 11.79 & 0 & $0 \cdot 36$ & $3 \cdot 29$ & $0 \cdot 35$ & 0.87 & $23 \cdot 48$ \\
\hline $\begin{array}{l}\text { S. saprophyticus } \\
179 / 92\end{array}$ & + & 0 & 1.63 & 0.48 & $9 \cdot 06$ & 0 & $0 \cdot 31$ & $2 \cdot 55$ & $0 \cdot 26$ & 0.72 & $15 \cdot 01$ \\
\hline $\begin{array}{l}\text { S. saprophyticus } \\
357 / 91\end{array}$ & - & 0 & 0 & 8.04 & $7 \cdot 21$ & 0 & 0.56 & 3.74 & 0.27 & $1 \cdot 03$ & $20 \cdot 85$ \\
\hline $\begin{array}{l}\text { S. saprophyticus } \\
358 / 91\end{array}$ & - & 0 & $9 \cdot 86$ & 1.05 & $7 \cdot 18$ & 0 & 0.57 & 3.89 & 0.41 & $1 \cdot 19$ & $24 \cdot 15$ \\
\hline $\begin{array}{l}\text { M. varians } \\
\text { CCM } 2253\end{array}$ & + & $5 \cdot 11$ & 0 & 0 & 42.81 & 0 & $0-24$ & $2 \cdot 02$ & 0 & 0.60 & $50 \cdot 78$ \\
\hline $\begin{array}{l}\text { M. kristinae } \\
\text { ATCC } 27571\end{array}$ & - & $4 \cdot 23$ & 0 & 0 & $26 \cdot 50$ & 0 & 0.59 & 4.96 & 0 & 0.69 & 36.97 \\
\hline
\end{tabular}

ability to grow on conalbumin $/ \alpha, \alpha^{\prime}$-bipyridyl-plates, although Micrococcus varians CCM 2253 produced a larger amount of $\alpha$-ketoacids than did the nongrowing M. kristinae ATCC 27571.

\section{Discussion}

Staphylococci, like other micro-organisms, employ different iron-supplying systems. These systems are adapted to the varying iron concentrations made available by different iron complexes. While it is well known that staphylococci are able to utilise the host iron compounds haemoglobin. lactoferrin and transferrin, the uptake mechanisms have not been precisely determined. ${ }^{32}$ Use of exogenous trihydroxamate-type siderophores such as ferrioxamine B or E by staphylococci was first described by Zähner et al. ${ }^{11}$ The different utilisation of ferrioxamines $B, E$ and $G$ by staphylococci has been employed as a diagnostic tool by Heuck et al. ${ }^{12}$

Hydroxamate- or catecholate-type siderophores have been shown to be absent in staphylococci. Two polyhydroxycarboxylate-type siderophores, staphyloferrin A and B were detected in S. aureus as well as in many CNS tested..$^{6.8 .9}$ Meiwes et al. ${ }^{6}$ described 34 staphylococcal strains producing staphyloferrin A when the medium was supplemented with D-ornithine, but only 11 strains were staphyloferrin A positive without supplementation. In 16 of 29 strains examined,
Haag et al. ${ }^{9}$ were able to detect staphyloferrin B. However, in some of the CNS, neither staphyloferrin A nor B was detected. The iron transport systems of the staphyloferrins A and B are commonly found in the staphylococci, and the system may be active also in the uptake of the structurally similar polyhydroxycarboxylate siderophore, rhizoferrin ${ }^{33}$ as shown in table I.

In all, 232 strains of $16 \mathrm{CNS}$ species and nine micrococcal strains of four species, varied in their ability to grow on iron-poor solid nutrient media such as conalbumin $/ \alpha, \alpha^{\prime}$-bipyridyl plates (table II). The ability of the six paired strains (growing and nongrowing) to grow in shaken liquid conalbumin $/ \alpha, \alpha^{\prime}$ bipyridyl medium probably depends on the improved aeration. In particular, the non-growing strains produced significantly higher amounts of $\alpha$-keto- $/ \alpha$ hydroxyacids (see below) to overcome iron limitation under those conditions. Recently, Drechsel et al. ${ }^{8}$ detected $\alpha$-keto- and $\alpha$-hydroxyacids as novel siderophores of the Proteus-Providencia-Morganella group. Testing of such compounds on S. epidermidis ATCC 14990 , with other siderophores as controls, resulted in positive bioassay reactions of the $\alpha$-keto- and $\alpha$ hydroxyacids except $\beta$-IP acid. Bioassay reactions appeared as expected in the cases of ferrioxamines, rhizoferrin and enterobactin. $\delta$-Aminolevulinic acid as a precursor of haem compounds supported growth of $S$. epidermidis ATCC 14990, exhibiting a possible metabolic pathway for such compounds in this strain. 
Relatively high amounts of $\alpha$-ketoacids were detected in supernates of the 12 selected CNS strains and of $M$. varians CCM 2253 and $M$. kristinae ATCC 27571 (table IV). The amounts of $\alpha$-ketoacids produced by these strains were significantly higher than those detected in E. coli. ${ }^{17}$ In particular, the nongrowing $S$. xylosus, $S$. cohnii and $S$. lentus exhibited very high total amounts of $\alpha$-ketoacids. Growing and non-growing $S$. cohnii strains can be distinguished by significant differences in the production of $\mathrm{PA}, \mathrm{KGA}$ and KBA (table IV) under the same iron-limited conditions. The other $\alpha$-ketoacids detected behaved quite similarly. Over-production of pyruvic acid by $E$. coli and S. typhimurium under iron-limited conditions has also been detected, ${ }^{17,18}$ especially in enterobactinnegative strains.

The $\alpha$-ketoacids produced by the CNS and micrococcal strains act as weak iron chelators in iron supply. They are not able to remove iron from conalbumin (data not shown). Furthermore, since growth promotion of S. epidermidis ATCC 14990 by $\alpha$-hydroxyacids was detected (table I), there is a need to confirm the presence of such compounds in the same supernates.

Growing and non-growing CNS strains also show differences in their ability to overcome iron stress in various iron-limited nutrient media. The $S$. lentus strain pair selected showed equal growth zones in bioassays of ferrioxamine $B$ and enterobactin under all iron-limited conditions (table III). The $\alpha$-ketoacids behaved similarly in the case of the non-growing $S$. lentus strain. The decreasing diameters of growth zones due to $\alpha$-ketoacids and overgrowth in the case of the growing strain at greater iron limitation $(60 \mu \mathrm{M}$ and $100 \mu \mathrm{M}$ EDDHA, respectively) may depend on the production of additional siderophores under these conditions (e.g., staphyloferrins). Furthermore, a possible change in the uptake systems of $\alpha$-ketoacids at different levels of iron limitation, obtained by addition of increasing amounts of EDDHA, can also be discussed. The other strain pairs behaved similarly (data not shown). Together with the quite similar composition of the detected $\alpha$-ketoacids, the strain

\section{References}

1. Pulverer G, Peters G, Schumacher-Perdreau F. Coagulasenegative staphylococci. Zentralbl Bakteriol Mikrobiol Hyg 1987; A264: 1-28.

2. Wilcox MH, Williams P, Smith DG, Modun B, Finch RG, Denyer SP. Variation in the expression of cell envelope proteins of coagulase-negative staphylococci cultured under iron-restricted conditions in human peritoneal dialysate. J Gen Microbiol 1991; 137: 2561-2570.

3. Konetschny-Rapp SG, Jung G, Meiwes J, Zähner H. Staphyloferrin A: a structurally new siderophore from staphylococci. Eur J Biochem 1990; 191 : 65-74.

4. Rabsch W, Reissbrodt R. Eisenversorgung von Bakterien und ihre Bedeutung für den infektiösen Prozeß. Bioforum 1992; 15: $10-15$.

5. Braun V, Fischer E, Hankte $K$, Rotering $H$. Iron as a signal in bacterial infections. In: Rott R, Goebel W (eds) Molecular basis of viral and microbial pathogenesis. Berlin, Springer 1988: 151-159. pairs of S. saprophyticus seemed to acquire iron from $\mathrm{Fe}^{3+}-\alpha$-ketoacids over a wide range of iron limitation.

All strains of the common species $S$. aureus, $S$. epidermidis and $S$. haemolyticus tested were able to grow on conalbumin $/ \alpha, \alpha^{\prime}$-bipyridyl medium, although $S$. epidermidis grew less well than $S$. aureus (table II). Therefore, they could not be differentiated by their ability to overcome iron stress under these conditions. Further investigations should determine the iron chelating mechanisms, and define the possible role for the common staphylococci as significant pathogens under impaired host defence mechanisms.

Recently, Lindsay and Riley ${ }^{15}$ also showed the ability of all $S$. aureus tested, to grow well under iron restricted conditions but poor growth of the CNS strains under these conditions. The $S$. aureus strains produced siderophores detected by the chrome azurol $S$ universal method in large quantities. In contrast, all the $S$. epidermidis strains tested and a few strains of three other CNS species produced low levels of iron chelators. They assume that CNS strains produce low levels of staphyloferrins, citrate or other unknown iron chelators (the lașt constitutively produced). These authors concluded that the better ability to grow under iron restricted conditions may contribute to the increased pathogenicity of $S$. aureus.

While the utilisation and production of $\alpha$-ketoacids by CNS are clearly involved in iron supply, further studies are needed to determine the significance of these compounds in the differentiation and characterisation of CNS and their relationships with other iron suppliers, such as staphyloferrins.

$\alpha$-Keto-/ $\alpha$-hydroxyacids seem to function in the iron supply of CNS and micrococci under different iron-limited conditions. It is likely that they can substitute as iron supply mechanisms when endogenous or exogenous iron carriers are not available. These compounds occur as primary metabolites in mammalian cells, so they can contribute to the multiplication of CNS and micrococci in eukaryotic hosts.

We appreciate the skilful technical assistance of I. G. Beer and E. Skiebe. Dr W. Witte is gratefully acknowledged for his critical reading of the manuscript.

6. Meiwes J, Fiedler H-P, Haag H, Zähner S, Konetschny-Rapp S, Jung $\mathrm{G}$. Isolation and characterisation of staphyloferrin A, a compound with siderophore activity from Staphylococcus hyicus DSM 20459. FEMS Microbiol Lett 1990; 67: 201-206.

7. Smith MJ, Shoolery JN, Schwyn B, Holden I, Neilands JB. Rhizobactin, a structurally novel siderophore from Rhizobium meliloti. J Am Chem Soc 1985; 107: 1739-1743.

8. Drechsel H, Freund S, Nicholson $\mathrm{G}$ et al. Purification and chemical characterization of staphyloferrin B, a hydrophilic siderophore from staphylococci. Biometals 1993; 6: 185-192.

9. Haag H, Fiedler H-P, Meiwes J, Drechsel H, Jung G, Zähner H. Isolation and biological characterization of staphyloferrin B, a compound with siderophore activity from staphylococci. FEMS Microbiol Lett 1994; 115: 125-130.

10. Meiwes J. Neue Siderophore aus Staphylokokken und Streptomyceten-Screening, Fermentation, Isolierung und Charakterisierung. Dissertation, Universität Tübingen, 1989. 
11. Zähner H, Hütter R, Brachmann E. Stoffwechselprodukte von Actinomyceten. 23. Mitt.: Zur Kenntnis der SideromycinWirkung. Arch Mikrobiol 1960: 36: 325-349.

12. Heuck D, Witte W, Braulke C. Reissbrodt R. Susceptibility to desferrioxamines and other chelators of coagulase-negative staphylococci. Int J Med Microbiol Virol Parasitol Infect Dis $1994 ; 280: 304-311$.

13. Marcelis JH, den Daas-Slagt JH. Hoogkamp-Korstanje JAA Iron requirement and chelator production of staphylococci, Streptococcus faecalis and Enterobacteriaceae. Antonie Van Leewienhoek J Microbiol Serol 1978: 44 $257-267$.

14. Williams P, Denyer SP. Finch RG. Protein antigens of Staphylococcus epidermidis grown under iron-restricted conditions in human peritoneal dialysate. FEMS Microbiol Lett 1988; 50: 29-33.

15. Lindsay JA, Riley TV. Staphylococcal iron requirements. siderophore production, and iron-regulated protein expression. Infect Immun 1994, 62: 2309-2314.

16. Drechsel H. Thieken A. Reissbrodt R. Jung G. Winkelmann G. $\alpha$-Ketoacids are novel siderophores in the genera Proteus Protidencia and Morganella and are produced by amino acid deaminases. $J$ Bacteriol 1993: 175: 2727-2733.

17. Reissbrodt R. Kühn S. Beer W. Braun V. Iron supply of $E$. colt by $\boldsymbol{x}$-ketoacids. In: International Conference on Iron and Microbial Iron Chelates. Brugge. Belgium, 1993

18. Reissbrodt R. Kingsley R. Rabsch W, Williams PH. $x$-Keto-/ $x$ hydroxyacids as novel siderophores of Salmonella. VAAMmeetings. Hannover. Germany. 1994.

19. Kingsley R. Rabsch W. Williams PH, Reissbrodt R. Eisenversorgung bei Salmonellen in Diagnostik, Epidemiologie und im Infektionsproze B. Immun Infekt 1994: 22: $10-14$.

20. Reissbrodt $R$, Erler W, Winkelmann G. Iron supply of Pasteurella multocida and Pasteurella haemolytica. J Basic Microbiol 1994; 34: 61-63.

21. Kloos WE, Lambe DW. Staphylococcus. In: Balows A, Hausler WJ. Herrmann KL, Isenberg HD. Shadomy HJ (eds)
Manual of clinical microbiology 5th edn. Washington DC, American Society for Microbiology. 1991: 222-236.

22. Braulke C, Witte W, Paul P. Species-Bestimmung koagulasenegativer Staphylokokken im Mikrotiter-Verfahren. Z Klin Med 1990; 45: 1737-1740.

23. Reissbrodt R, Rabsch W, Chapearouge A, Jung G, Winkelmann $\mathrm{G}$. Isolation and identification of ferrioxamine $\mathrm{G}$ and $\mathrm{E}$ in Hafnia alvei. Biometals 1990; 3: 54-60.

24. Neilands JB, Nakamura K. Detection, determination, isolation, characterization and regulation of microbial iron chelates. In: Winkelmann G (ed) CRC Handbook of microbial iron chelates. Boca Raton, CRC Press. 1991: 1-14.

25. Konetschny-Rapp S, Huschka H, Winkelmann G, Jung G. High performance liquid chromatography of siderophores from fungi. Biometals $1988 ; 1: 18-25$.

26. Hayashi T. Tsuchiya $H$, Todoriki $H$, Naruse $H$. Highperformance liquid chromatographic determination of $\alpha$ ketoacids in human urine and plasma. Anal Biochem 1982; 122: 173-179.

27. Rogers $\mathbf{H J}$. Iron-binding catechols and virulence in Escherichia coli. Infect Immun 1973; 7: 445-456.

28. Flossman KD, Grajetzki CH, Rosner H. Nachweis von EisenTransport-Aktivität in Pasteurella multocida-Kulturen J Basic Microbiol 1985; 25: 559-567.

29. Stevenson P, Griffith E. Growth of Escherichia coli under ironrestricted conditions. In: Sussman $M$ (ed) The virulence of Escherichia coli. London, Academic Press. 1985: 413-418.

30. Miles AA, Khimji PL. Enterobacterial chelators of iron: their occurrence, detection, and relation to pathogenicity. $J \mathrm{Med}$ Microbiol 1975; 8: 477-490.

31. Reissbrodt R, Rabsch W. Further differentiation of Enterobacteriaceae by means of siderophore-pattern analysis. Zentralbl Bakteriol $H_{y g}$ 1988; A268: 306-317.

32. Naidu AS, Andersson M, Forsgren A. Identification of a human lactoferrin-binding protein in Staphylococcus aureus. J Med Microbiol 1992; 36: 177-183.

33. Drechsel H, Metzger J, Freund S, Jung G, Boelaert G, Winkelmann G. Rhizoferrin-a novel siderophore from the fungus Rhizopus microsporus var. rhizopodiformis. Biometals 1991; 4: 238-243. 